\title{
Ueber die Einwirkung des Lichtes auf Gemische von chromsauren Salzen (resp. Chromsäure), Alkohol und extrahirten organischen Substanzen. Technische Mittheilung.
}

Von

Dr. Mans Virchow,

II. Prosektor am anatomischen Institut zu Berlin.

Wie bekannt werden in der Photographie und in den mit Huilfe der Photographie arbeitenden mechanischen Reproductionsrerfahren die chromsauren Salze in ausgedehnter Weise verwendet.

Es lag daher nahe zu beachten, ob nicht auch in Flissigkeiten, welche man erbält, wenn Thiere, Organe oder Gewebsstücke, die in Lösungen chromsaurer Salze einige Zeit waren, in Alkohol gebracht werden - ob nicht in solchen Flüssigkeiten gleichfalls dureh die Einwirkung des Lichtes Niedersehläge und zwar hier als störende Nebenprodukte entstehen. Es ist das in der That der Fall und zwar in sehr bemerkenswerther Weise. Jedenfalls ist aber dieser Umstand in der mikroskopischen Technik nicht allgemein beachtet, und ich möchte daher die Anfmerksamkeit darauf umsomehr lenken, als man durch konsequente Fernbaltung des Lichtes die unangenehmen Niederschlïge vollkommen vermeiden kann.

Folgende Versuche, die ich mit Rücksicht auf den angeregten Punkt anstellte, mögen der Sache eine bestimmtere Form geben. Eine Partie von Riickenmarksstiicken wurde so wie sie aus der Müller'schen Flüssigkeit kam, in Alkohol von $95 \%$ gelegt und dann ins Dunkle gestellt. Nach mehreren Tagen wurde der dunkelgelb gewordene klare Alkohol abgegossen und eine Probe davon im Dunkeln aufbewahrt, das Uebrige dem Lichte ausgesetzt. Durch die Lichtwirkung trat zunächst eine Bräunung, dann eine Trübung and dann allnählich eine Ausscheidung brauner Flocken ein, welche sich langsam zu Boden setzten. Auch nachdem die Flocken sich gesetzt hatten, blieb die Flüssigkeit trübe. Von Zeitangaben sehe ich hier völlig ab, da dieselben je nach der Helligkeit, die bei den mehrfach angestellten Versuchen herrschte, verschieden laufen würden. Die Fliissigkeit wurde filtrirt, ging klar durch's Filter und war gelb mit einem Stich in's Grüne. Der Rüekstand erschien in dünner Lage auf 
Glas rothbraun, im Filter dunkel chokoladefarben, bei der nikroskopischen Betrachtung zeigte er sich zusammengesetzt aus gleich grossen, sebr feinen Körnchen. Aus der klar abgelaufenen gelben Flïssigkeit wurde durch erneuerte Lichtwirkung ein grauer flockiger Niederschlag ausgefällt, beim Filtriren lief eine klare hellgelbe Flüssigkeit ab. Durch erneuerte Lichtwirkung entstand ein schlammiger, fast weisser Niederschlag, nach dem Abfiltriren war die Fluissigkeit fast farblos. Auch aus dieser liess slch noch einmal durch Lichtwirkung ein unbedeutender Satz abscheiden, und es blieb sodann nach dem Filtriren eine wasserklare Flüssigkeit zurtick.

Von den vier Filtraten und von der Stammflussigkeit wurden Proben wochenlang aufbewahrt, wobei sich allerdings leichte Trübungen einstellten in Folge des schwachen Lichtes, welches in den öfters geöffneten Schrank einfiel. Die Stammflüssigkeit glich in der Farbenstärke einem Gemisch von $90 \mathrm{Th}$. Wasser mit $10 \mathrm{Th}$. Müller'scher Flüssigkeit, das erste Filtrat einem Gemisch von 99 Th. Wasser mit $1 \mathrm{Th}$. Müller'scher Flüssigkeit, das zweite einem Gemisch, in welchem $0,3 \%$ Müller'scher Flüssigkeit enthalten sind. Die fraktionirte, d. h. die wiederholte, durch Abfiltriren der Niederschläge unterbrochene Belichtung fiulut nach meiner Erfahrung weit schneller wie die ununterbrochene zu dem Endresultat einer farblosen, durch Lichtwirkung nicht melur sich triubenden Flïssigkeit.

Indessen ist diese "gereinigte" Flüssigkeit kein reiner Alkohol. Abgesehen von einer gewissen Menge von Aldehyd, welche dieselbe enthalten wird, hat sie gelöst Substanzen, die durch Wasser ausgefällt werden können und der durch Wasserzusatz entstehende feine weisse Schlamm geht durch's Filter hindurch. Trotzdem eignet sich die gereinigte Fluissigkeit sehr gut, wovon ich mich tiberzengt habe, zum Erhärten, ja es ist dic Frage, ob es nicht zweckmässig wäre, zur Erhärtung des centralen Nervensystemes gerade solchen Alkohol zu verwenden, der schon Bestandtheile des Nervenmarkes in gewisser Menge gelöst enthält und demgemäss die zu erhärtenden Stticke weniger auslangt.

Das sind jedoch Betrachtungen, die der nächsten Absicht dieser Mittheilung fern liegen. Dagegen bemerke ich, dass das Ergebniss des Versuches ganz entsprechend ausfällt, wenn man für Rückenmark irgend ein anderes Organ: Leber, Niere, Auge u. s. w. und für Müller'sche Flüssigkeit Chromsüure setzt. Im 
Einzelnen wïrde man natürlich bei derartigen Versuchen bedeutende $\mathrm{Abweichungen} \mathrm{finden,} \mathrm{und} \mathrm{ich} \mathrm{beschränke} \mathrm{mich} \mathrm{daher} \mathrm{darauf,}$ als technischen Rath anzugeben, dass man Stücke, die in Muller'scher Flïssigkeit oder Chromsäure vorbehandelt sind, während des Härtens in Alkohol im Dunkeln aufbewahre und zwar so lange, bis der (öfters erneute) Alkohol keine Färbung mehr annimmt. Ob man zwischen die Behandlung mit Mäller'scher Flüssigkeit und die Härtung in Alkohol ein Auswässern einschiebt, ändert an der Vorsehrift nichts. Vielleicht kann man aber, wenn man die hier angerathene Vorsicht anwendet, das Auswässern umgehen oder doch abkürzen, was oft sehr angenehm ist.

Wie weit die Alkoholbehandlung im Dunkeln für die verschiedenen Organe von Nutzen ist, vermag ich nicht anzugeben. Bei Stücken eines Rückenmarkes jedoch, welches 6 bis 8 Wochen in Müller'scher Flüssigkeit gewesen war, zeigte sich nach der Alkoholbehandlung ohne vorhergehendes Auswässern eine schöne bräunliche Färbung der Schnittfläche und die Schnitte nahmen eine gute Karmintinktion (durch Weigert'sches Pikrokarmin) an.

Uebrigens will ich hinzufügen, dass, wenn die Stücke erst entwässert sind, sie in absolutem Alkohol auch am Lichte stehen können, und dass dann kein Niederschlag mehr eintritt, wenn auch der Alkohol noch Färbung annimmt.

Der Vortheil der Erhärtung im Dunkeln besteht darin, dass sich weder im Alkohol die unangenehmen schlammigen Niederschläge bilden, noch - was wichtiger ist - in den vom Lichte getroffenen Oberflächen der Präparate die mikroskopisch feinen Ablagerungen, welche die Feinheit eines galvanoplastischen Niederschlages haben und gewiss die Diffusion zwischen dem Innern des Präparates und der umgebenden Flüssigkeit erschweren, so dass sich bei der weitern Konservirung manches im Innern des Gewebes niederschlagen muss, was sonst entfernt worden wäre.

Wenn wirklich die Erhärtungs- und Färbetechnik in Chemie verwandelt werden soll, so dürfen auch physikalische Vorgänge, zumal wo es sich um so handgreifliche und exakt definirbare Effekte handelt, nicht unbeachtet bleiben. 